\title{
Agricultura Familiar e Agroindústria Canavieira: impasses sociais
}

\author{
Simone Pereira de Carvalho ${ }^{1}$ \\ Joel Orlando Bevilaqua Marin ${ }^{2,3}$
}

Resumo: A Política Agroenergética para produção de biocombustíveis é apresentada sob os pressupostos do desenvolvimento sustentável. O álcool, produzido a partir da cana-de-açúcar, aparece como a alternativa mais viável, o que estimula a expansão e redistribuição espacial da produção canavieira. $\mathrm{O}$ estado de Goiás está entre as principais rotas de ampliação da cana. O objetivo do artigo é compreender o debate das questões sociais no plano dos discursos oficiais em torno do Plano Nacional de Agroenergia, bem como as contradições sociais associadas à expansão da monocultura canavieira em regióes de predomínio da agricultura familiar. O desenvolvimento do tema baseou-se num estudo de caso, realizado no município de Itapuranga (GO), valendo-se de uma abordagem qualitativa e da combinação das técnicas de pesquisa bibliográfica, observação e, principalmente, entrevistas. Constatou-se que a expansão do cultivo da cana-de-açúcar contribuiu para transformar o contexto social de Itapuranga e provocar alterações consideráveis na dinâmica produtiva e organizacional dos agricultores familiares.

Palavras-chave: Política agroenergética, Agricultura familiar, Agroindústria canavieira.

Abstract: Agroenergetic Policies for the production of biofuels is presented under the assumptions of sustainable development. The ethanol fuel, produced from sugarcane, appears as a more viable alternative, which stimulates growth of new processes and

1 Mestre em Agronegócios (EA-PPAGRO/Universidade Federal de Goiás). E-mail: siimoni@gmail.com

2 Doutor em Sociologia (Unesp). Professor da Universidade Federal de Santa Maria. E-mail: bevilaquamarin@gmail.com

3 Este artigo é parte da dissertação intitulada Agricultura familiar e agroindústria canavieira: integrações e contradições, que recebeu, em 2009, o Prêmio Sober. 
spatial distribution of the sugarcane production. Goiás state is one of the main routes of expansion of the sugarcane. This article aims to understand the contradictions of the social issues within the official discourse of the National Plan of Agroenergy and the impacts associated with the expansion of sugarcane monoculture in regions of predominance of family farming. The development of the theme is based on a case study, conducted in Itapuranga city (Goiás state), using a qualitative approach and combining the techniques of literature search, observation and interviews. It was found that these policies helped to transform the social context of Itapuranga and cause considerable changes in the organizational dynamics of family farmers.

Key-words: Agroenergetic policy, Family farming, Sugarcane agribusiness.

\section{Classificação JEL: Q16.}

\section{Introdução}

Os problemas relacionados à crise energética mundial obrigaram o Estado a retomar as políticas agroenergéticas para produção de biocombustíveis, materializadas no Plano Nacional de Agroenergia (2006-2011). A produção de álcool a partir da cana-de-açúcar é apresentada como a alternativa mais viável para enfrentar a crise energética e para a construção do desenvolvimento sustentável. A retomada das políticas agroenergéticas está provocando uma nova expansão do setor canavieiro, marcada por uma redistribuição espacial da produção, com tendências de aumento nos estados de Mato Grosso, Mato Grosso do Sul, Minas Gerais e Goiás.

Os atrativos de Goiás referem-se ao baixo preço das terras, clima favorável, incentivos fiscais e, principalmente, a localização geográfica, que facilita o escoamento da produção. Em função disso, vem crescendo o número de agroindústrias canavieiras em funcionamento no estado que, em 2009, somaram 33 (UDOP, 2009). As agroindústrias canavieiras têm a capacidade de provocar alterações relevantes nos municípios onde se inserem, repercutindo especialmente na vida dos agricultores que se integram à agroindústria. $\mathrm{O}$ governo prevê que a expansão da cultura da cana no estado se dará em áreas de pastagens. Porém, há evidências de que a produção de cana-de-açúcar está adentrando em região de reconhecida importância de agricultura familiar, situação já visível em alguns municípios goianos, como em Itapuranga (GO). No entanto, pouco se sabe acerca das repercussões sociais que esse processo pode desencadear.

Este artigo tem por objetivo analisar os desdobramentos sociais decorrentes da implantação de uma agroindústria canavieira numa área de predomínio 
de agricultura familiar. Foram abordadas questões referentes à geração de empregos, aos impactos na oferta de mão de obra local, à migração, ao aumento da violência, bem como às transformações dos sistemas de produção dos agricultores familiares com a substituição de culturas alimentares e da atividade pecuária pela cultura canavieira.

\section{Questões metodológicas}

Por meio de discursos, projetos, programas ou planos políticos, o Estado impõe seu ponto de vista, que se institui como a visão legítima que todos devem reconhecer, ao menos dentro dos limites de uma determinada sociedade. Dessa forma, o Estado explora a possibilidade de mudar o mundo social modificando a representação do mundo através de uma pré-visão, que, na condição de "previsão", contribui para a construção da realidade que anuncia e para a produção de um novo senso comum (BOURDIEU, 1998a).

Nos discursos oficiais relacionados ao Programa Nacional de Agroenergia, o Estado, por meio de seus representantes legítimos, apresenta sua visão de mundo como se fosse uma demanda social extraída da coletividade. Dessa forma, o então ministro da Agricultura Pecuária e Abastecimento (Mapa) se manifesta: "Conclamamos [...] a sociedade em geral a se integrarem [sic] neste esforço nacional, para transformar estas oportunidades em realizações. Juntos, vamos construir um novo paradigma de desenvolvimento, em bases sustentáveis da nossa agroenergia" (MAPA et al., 2005a, p. 3). Bourdieu (1990) explica que, nesses casos, o interesse particular do Estado esconde-se atrás do interesse do povo, e este substitui a visão de mundo do povo, ao qual deveria representar, pela visão de mundo do Estado.

Segundo Bourdieu (1990), a visão de mundo do Estado se exprime nos discursos oficiais quando este impõe seu ponto de vista legítimo, ao qual toda sociedade deve reconhecer. Em relação ao programa agroenergético, num primeiro momento, o discurso oficial fez um diagnóstico dos problemas ligados à matriz energética. $\mathrm{O}$ diagnóstico apontou que as atuais reservas de petróleo durarão apenas 40 anos, se forem mantidos os atuais níveis de consumo, mas a previsão é que a demanda cresça elevando os preços. Isto será agravado pelas mudanças climáticas globais devido às expectativas de incorporação dos custos ambientais aos preços dos combustíveis fósseis. Soma-se a isso o fato de $75,2 \%$ das reservas de petróleo localizarem-se no Oriente Médio e em parte na Venezuela, o que impõe uma forte dependência de países assolados por conflitos regionais e/ou disputas políticas. Essas questões colocam a necessidade de se investir em fontes energéticas mais seguras ou, como prefere o Estado, mais sustentáveis, com oferta e preços mais estáveis (MAPA et al., 2005a). 
Em suma, de acordo com o ponto de vista oficial, o Brasil e o mundo encontram-se na iminência de uma crise energética, o que impõe a necessidade de se intensificar a produção de energia a partir da biomassa. Essa opção é defendida como a mais viável, não apenas sob o ponto de vista econômico, mas também social, uma vez que essa política possibilitaria a promoção do propalado desenvolvimento sustentável (MAPA et al., 2005a, MAPA et al., 2005b, MAPA e SPA, 2006). Esse enfoque funciona muitas vezes como uma ideologia, ou seja, uma arma para o exercício da violência do Estado, que se dá pela imposição de um consenso de que o anunciado é bom para todos e responde aos anseios coletivos.

No conjunto das propostas para a promoção do desenvolvimento sustentável, o Estado brasileiro aborda a inserção da agricultura familiar na política agroenergética como uma forma de promoção da inclusão social nas camadas menos favorecidas. Como os agricultores familiares são objeto de análise deste estudo, torna-se necessário compreender conceitualmente a forma de organização social dos agricultores que se enquadram nessa categoria. Mas, primeiramente, far-se-á uma reflexão conceitual dessa categoria social sob a perspectiva teórica proposta por Neves (2007).

Segundo Neves (2007), o termo agricultura familiar começou a ser utilizado em 1990, nos campos acadêmicos americano e europeu, para designar o modelo de integração entre a agricultura e a agroindústria. No Brasil, foi primeiramente empregado por pesquisadores multidisciplinares e por representantes políticos dos trabalhadores rurais. Os agentes políticos objetivavam instituir uma categoria classificatória dotada de direitos sociais, ou seja, queriam definir outra representação da sociedade e, assim assegurar o reconhecimento e a legitimidade das ações políticas de grupos que buscavam um enquadramento social, como os trabalhadores rurais, os assentados e os agricultores parcelares.

Para Neves (2007), as pesquisadoras Bergamasco e Wanderley, entre outros colaboradores, ao organizarem um número temático em defesa da agricultura familiar na revista Reforma Agrária da Associação Brasileira de Reforma Agrária (v. 25, no 2 e 3, mai./dez. 1995), contribuíram para a consagração desse termo no meio científico brasileiro e nos grupos mobilizados para constituição de políticas de apoio aos agricultores que poderiam assim ser enquadrados. A autora afirma que, também Veiga (1995), ao delimitar o termo agricultura familiar, fez com que se substituíssem antigas categorias utilizadas - camponeses, produção familiar e pequena produção - pelo termo agricultura familiar. Essa simplificação dificultou a compreensão do heterogêneo segmento de agricultores existentes no meio rural brasileiro, pois o termo passou a designar um grande número de agricultores submetidos a contextos muito diversificados, encobrindo as especificidades de cada grupo.

No intuito de atender às demandas reivindicatórias de grupos que lutavam pela instituição de uma categoria classificatória dotada de direitos sociais, o 
Estado adotou uma categorização normativa que busca contemplar o maior número possível de agentes sociais, enquadrando-os como agricultor familiar. Para essa categorização, o Estado utiliza parâmetros relacionados ao tamanho da área, à utilização da mão de obra familiar, à gestão do empreendimento e à proporção da renda auferida no estabelecimento. Assim, no art. 3o da Lei no 11.326 de 24/07/2006, o Estado estabelece a conceituação de empreendedor familiar rural enquadrando como agricultores familiares aqueles que praticam atividades no meio rural e que atendem simultaneamente aos seguintes requisitos:

1. Possuir área de terra sob título de proprietário, meeiro, parceiro ou arrendatário inferior a quatro módulos fiscais;

2. Utilizar predominantemente mão de obra familiar nas atividades econômicas do seu estabelecimento ou empreendimento;

3. Ter renda familiar originada predominantemente de atividades vinculadas ao próprio estabelecimento;

4. Administrar e dirigir o estabelecimento com a própria família (BRASIL, 2006).

Neves (2007) ressalta que o termo agricultura familiar também pode ser utilizado para designar um setor produtivo dotado de características ou "valores" associados à sustentabilidade socioambiental. Os defensores da ideia pretendem eleger junto ao Estado a "agricultura familiar" como a categoria que melhor atende as exigências desse novo padrão de produção baseado numa agricultura produtiva, socialmente justa e ambientalmente correta.

Esse enfoque permeia o Programa Nacional de Agroenergia: "A especialização da agricultura familiar está na capacidade de desenvolvimento de várias atividades simultâneas. É essa característica dos sistemas produtivos familiares que garante a biodiversidade dos agroecossistemas" (MAPA et al., 2005a, p. 26). Assim, o Estado destaca a agricultura familiar como peça-chave para promoção do desenvolvimento sustentável.

Neves (2007) observa que a distinção da agricultura familiar com base em aspectos valorativos como a ênfase na diversificação, na preservação da biodiversidade, dentre outros, não é generalizável a todos os agricultores ditos familiares, mas, sim desejável, contribuindo apenas para reafirmar que o termo agricultura familiar apresenta-se como uma categoria de mobilização política. No exercício de construção de uma categoria produtiva desejada, os autores cumprem o dever de restituir o caráter sociológico do termo que tem sua eficácia política pelo fato de criar posições e direitos correspondentes. No entanto, esses raciocínios são passíveis de novas interpretações e contra-argumentações.

Em suma, Neves observa que o termo agricultura familiar é conceitualmente ambíguo e demasiadamente amplo, se prestando mais para uma categorização socioprofissional do que propriamente para a definição de um 
segmento de agricultores. Para uma melhor compreensão dos agricultores, a autora propõe seu estudo a partir das redes sociais em que estão inseridos. Sob essa perspectiva, devem ser compreendidos com base nas particularidades que tecem no seu espaço social e pelos parâmetros que regem sua realidade, ou seja, suas múltiplas formas de inserção social, atitudes, visões e comportamentos.

Levando-se em consideração as questões teórico-metodológicas apontadas, fez se um estudo de caso buscando apreender e problematizar o processo de expansão da cultura da cana-de-açúcar em Itapuranga (GO), a partir das relações sociais em que os agricultores familiares estão envolvidos, procurando evidenciar as diferentes percepções dos diversos agentes sociais.

\subsection{Operacionalização do Estudo de Caso}

Bourdieu (1997) explica que, para compreender o que se passa em um lugar que abriga pessoas diferentes, não basta dar razão aos pontos de vista tomados separadamente, é necessário confrontá-los em sua realidade com o intuito de favorecer a lucidez. Ademais, não há como estabelecer a lógica do mundo social, a não ser por meio do estudo particular de uma realidade empírica, historicamente situada e datada. Para compreender as contradições tecidas no âmbito da atual política agroenergética brasileira fez-se um estudo de caso em Itapuranga (GO), município marcado pela importância da agricultura familiar e que atualmente convive com a expansão da cultura agroenergética cana-de-açúcar em seu território.

Itapuranga localiza-se no território da cidadania Vale do Rio Vermelho e pertence à mesorregião Centro Goiano e microrregião de Ceres. O município ocupa uma área de $1.277,2 \mathrm{~km}^{2}$, sendo formado pelos distritos de Cibele e Diolândia e pelos aglomerados rurais de Lages e São José (SEPLAN/SEPIN, 2009). Segundo Brandão (1986), a origem do município remonta à fase do ciclo do ouro (século XVIII), mas, nesse período, a região serviu apenas como local de passagem entre os arraiais do ouro, sem grandes significados econômicos. Em 1933, foi requerido o título de posse das terras que deram origem ao povoado de Xixá, pertencente ao município de Goiás. Posteriormente, no contexto da "Marcha para o Oeste", o povoado foi elevado à categoria de município com a denominação de Itapuranga - conforme Lei no 748 de 1953.

$\mathrm{Na}$ ocasião, foram atraídos para a região agricultores provenientes de outros estados, dando início à atual conformação do município, marcada pela predominância de agricultores familiares estabelecidos em pequenos lotes de terra. Segundo o Agropecuário (1996), aproximadamente 91,8\% dos estabelecimentos rurais de Itapuranga enquadram-se como familiar. Estes agricultores movimentam a economia local e são responsáveis por $65,7 \%$ do Valor Anual Bruto da Produção Agropecuária. Há predomínio de pequenas 
propriedades, $83 \%$ dos imóveis rurais possuem área inferior a 80 hectares (ha), sendo que a dimensão do Módulo Fiscal do município é de 20 ha. As propriedades normalmente são exploradas e geridas pela própria família, com eventual contratação de mão de obra assalariada.

Itapuranga apresenta bons indicadores referentes ao nível de saúde, à oferta de serviços básicos e à infraestrutura. O Índice de Desenvolvimento Humano do município é classificado como médio, porém, apresenta baixo PIB per capita e baixa arrecadação de impostos (SEPLAN/SEPIN, 2009). Na expectativa de aumentar a arrecadação de impostos, o poder político local empenhou-se no crescimento da produção de álcool.

Cabe destacar que, no contexto da segunda fase do Proálcool, a população de Itapuranga conviveu com a expansão do cultivo da cana em seu território, quando foi instalada no município a Agroindústria Pite S/A. Essa agroindústria foi desativada ainda na década de 1980, retomando suas atividades somente em 2005, quando o Grupo Farias - Vale Verde Empreendimentos Agrícolas Ltda. - alugou as instalações da antiga Pite S/A. Assim, a reintrodução da cana no município está em fase de consolidação. Todavia, o processo de expansão da cana, desencadeado pela nova conjuntura da política agroenergética, está permeado por tensões, conflitos de interesses e contradições sociais.

Para o desenvolvimento do tema proposto, utiliza-se uma abordagem qualitativa, realizada com a combinação de várias técnicas de pesquisa, como a bibliográfica, entrevistas e a observação. Os dados foram obtidos principalmente, por meio de entrevistas realizadas junto aos agricultores familiares de Itapuranga. Foram entrevistadas quinze famílias; desse total, onze agricultores se integraram à agroindústria canavieira. A amostragem obedeceu a critérios não probabilistas, com o propósito de captar as razões da integração e os problemas advindos da expansão canavieira. Assim, nas entrevistas, foram privilegiados os aspectos qualitativos, estimulando o envolvimento e a participação dos membros da família no intuito de se obter uma abordagem ampla e sistêmica do problema em estudo, procurando dar visibilidade aos distintos pontos de vista e visões, com vistas a melhor explicitar a realidade dos agricultores. Como ressalta Bourdieu (1990, p. 156):

A "realidade social" [...] também é um objeto de percepção. E a ciência social deve tomar como objeto não apenas essa realidade, mas também a percepção dessa realidade, as perspectivas, os pontos de vista que, em função da posição que ocupam no espaço social objetivo, os agentes têm sobre essa realidade.

Em relação à amostra de agricultores familiares, observa-se que a maioria explora a terra na condição de proprietário; no entanto, estabelecem relações de parceira ou arrendam terra de outros agricultores. Cerca de $94 \%$ dos imóveis rurais enquadram-se como pequena propriedade e as terras são exploradas e 
geridas pelo casal proprietário. Do total de agricultores pesquisados, $87 \%$ não possuem máquinas ou implementos agrícolas mecanizados, mas utilizam-nos especialmente nas etapas de preparo do solo via locação de serviços terceirizados. Os agricultores empregam basicamente mão de obra familiar e contratam diaristas para os períodos de pico do ciclo produtivo. Seus sistemas produtivos são diversificados, visando atender às necessidades alimentares da família e à comercialização. Com esse intuito, combinam a produção de gêneros alimentícios, o cultivo de hortaliças, frutíferas e ainda a criação de animais bovinos, suínos e galinhas.

Além dos agricultores, foram entrevistados outros agentes sociais envolvidos com a questão, como o presidente do Sindicato dos Empregadores Rurais de Itapuranga, o presidente do Sindicato dos Trabalhadores Rurais de Itapuranga, um representante da Igreja Católica, o Secretário da Agricultura do município, o Secretário do Meio Ambiente, o presidente da Organização dos Amigos de Itapuranga (OAI), um engenheiro agrônomo da Agência Goiana de Desenvolvimento Rural e Fundiário (Agencia Rural), o presidente da Câmara dos Dirigentes Lojistas e uma representante da Cooperativa dos Agricultores Familiares de Itapuranga (Cooperafi). Também foram entrevistados agentes ligados à agroindústria, como funcionários, prestadores de serviço e um grupo de cortadores de cana.

Nas entrevistas feitas com os líderes sindicais, o representante da cooperativa e da Igreja Católica, buscou-se apreender seus pontos de vista, opiniões, bem como as influências que exercem nos agricultores familiares. Nas entrevistas dirigidas aos representantes políticos, buscou-se captar o posicionamento do poder estatal local e suas percepções sobre os problemas sociais relacionados à cultura canavieira. Em relação à OAI - organização que apoiou a instalação da agroindústria no município -, buscou-se compreender suas motivações e perspectivas em relação ao processo que ajudou a consolidar. Já o presidente da Câmara dos Dirigentes Lojistas informou sobre as transformações econômicas decorrentes da vinda da agroindústria para o município. Por fim, os trabalhadores da agroindústria falaram sobre as particularidades do mercado de trabalho.

\section{A agroindústria canavieira e suas contradições sociais}

Durante o Proálcool, a geração de emprego foi uma das principais justificativas utilizadas pelo Estado para legitimar os investimentos no setor canavieiro. Segundo Magalhães et al. (1991), o Programa gerou dois tipos fundamentais de empregos: os empregos diretos, vinculados à operação nas destilarias e nas lavouras de cana-de-açúcar, e os empregos diretos e indiretos, resultantes da aquisição de insumos. Os autores estimam que, em 1985, foram gerados 828.000 novos empregos e destes, 625.000 empregos diretos no setor 
sucroalcooleiro, abrangendo as atividades agrícolas e industriais. Foram gerados 202.804 empregos diretos e indiretos, resultantes da aquisição de insumos que envolviam as operações e os investimentos industriais e agrícolas.

Novamente no contexto do atual programa de agroenergia, a possibilidade de geração de empregos é difundida como um dos trunfos da agroindústria canavieira. Os postos de trabalhos concentram-se principalmente na etapa do corte da cana. Embora não existam estudos definitivos comparando a geração de emprego no setor de energia de carbono fóssil - cadeia do petróleo - e de agroenergia, acredita-se que é possível gerar de 10 a 20 vezes mais empregos na agricultura de agroenergia. Outra vantagem apontada deve-se ao fato de os empregos serem gerados internamente. Assim, o Estado defende que "com uma única política pública: através do incentivo à agricultura de energia, é possível enfrentar os desafios da produção de energia sustentável, [...] da geração de emprego e renda, com distribuição mais equitativa" (MAPA et al., 2005b, p. 17).

Dessa forma, a geração de empregos pelo complexo canavieiro torna-se ponto-chave das propostas voltadas ao desenvolvimento social. Teoricamente, com a ampliação dos postos de trabalho, os trabalhadores teriam acesso a uma remuneração que lhes possibilitariam o consumo e movimentaria a economia local dos municípios. Isso causaria a tão sonhada renda no meio rural, promovendo a propalada justiça social no contexto do país. O acesso ao trabalho e ao consumo constitui um dos principais mecanismos de promoção da inclusão social, embutidos na política agroenergética.

Segundo dados da Seplan/Sepin (2008) o setor sucroalcooleiro desempenhou, em 2007, um importante papel na geração de empregos em Goiás. As atividades de cultivo da cana-de-açúcar, produção de álcool e fabricação e refino de açúcar foram responsáveis pela geração de mais de 22 mil postos de trabalho, o que corresponde a $44,31 \%$ da soma de todos os empregos gerados no acumulado do ano.

Nas entrevistas realizadas em Itapuranga (GO), a geração de empregos foi apontada como o principal benefício decorrente da implantação da agroindústria no município, visto que o desemprego era um problema social que incidia sobre a população, remontando dentre os motivos que levaram a OAI a empenhar-se para atrair a agroindústria para o município. Segundo dados da Seplan/ Sepin (2009), o saldo entre admissão e desligamento em Itapuranga foi negativo entre 2004 e 2005, tornando a se elevar em 2006. Tudo indica que o início das atividades da agroindústria canavieira no município contribuiu para o aumento da geração de empregos.

A agroindústria canavieira é a principal fonte de absorção de mão de obra, tanto em Itapuranga como nas regiões circunvizinhas. Pela análise dos depoimentos orais dos diferentes agentes sociais entrevistados no município, percebe-se certo consenso ao apontar a geração de postos de trabalho como o principal aspecto positivo decorrente da implantação da agroindústria na região. 
Em meio ao desemprego, a qualidade dos postos de trabalho gerados pelo empreendimento canavieiro é pouco problematizada pela população. $\mathrm{O}$ presidente da OAI, quando indagado acerca das condições precárias e aviltantes dos empregos gerados, desqualifica tais questionamentos, tachando-os de "preconceito ao trabalho braçal" que, a seu ver, é um trabalho como outro qualquer, apenas um pouco mais exaustivo. A maioria dos entrevistados também não questiona a qualidade dos empregos gerados. Estes demonstram imensa satisfação com a geração de empregos, tido como o pressuposto necessário para geração de renda e a dinamização da economia local.

Segundo Bourdieu (1998b, p. 120, 122, 123), os efeitos do desemprego são visíveis, pois se percebe uma desestruturação da vida familiar e social, além da relação que as pessoas mantêm com o mundo. O efeito devastador do desemprego resulta numa espécie de submissão, o que impede qualquer "antecipação racional", na medida em que torna o futuro incerto, "sem um mínimo de crença e de esperança que é preciso ter para se revoltar" contra a intolerável situação vivenciada. Quando o desemprego atinge taxas elevadas e a precariedade afeta grande parte da população, "o trabalho se torna uma coisa rara, desejável a qualquer preço", circunscreve-se, então, um novo tipo de dominação caracterizada por uma situação generalizada e permanente de insegurança.

A insegurança em relação ao emprego não afeta somente o conjunto de trabalhadores diretamente ameaçados, mas provoca uma insegurança generalizada na sociedade como um todo, afetando até mesmo aqueles que não estão ou não serão diretamente atingidos. Segundo Bourdieu (1998b, p. 121),

essa espécie de 'mentalidade coletiva' [...], comum a toda a época, está no princípio da desmoralização e da desmobilização que se podem observar [...] em países subdesenvolvidos, afligidos por taxas de desemprego ou de subemprego muito elevadas e habitados permanentemente pela obsessão do desemprego.

A geração de postos de trabalho pela agroindústria canavieira em Itapuranga, na maioria das vezes, foi ressaltada pela comunidade local como uma aceitável compensação pelas atividades que nem sempre aprovam, como a poluição, as queimadas, o uso generalizado da água do córrego Canastra, o uso de agrotóxicos, a derrubada das árvores, entre outros.

A insegurança gerada pelo desemprego, da qual fala Bourdieu, pôde ser evidenciada na falta de questionamento social acerca da qualidade dos postos de trabalhos gerados pela agroindústria, bem como no fato de a comunidade optar pelo emprego ao invés da eliminação da queima da cana via introdução da colhedora mecânica e, ainda, pela preocupação da sociedade com o fim da safra na agroindústria - ocasião em que ocorre a rescisão dos contratos de trabalho temporários. O presidente da Câmara de Dirigentes Lojistas (CDL) de Itapuranga (GO) afirmou que o desemprego não oferece uma ameaça direta 
para os comerciantes, porém, estes demonstram insegurança e preocupação com a questão.

Com a ameaça de desemprego, problema cada vez mais presente no cotidiano, os trabalhadores acabam por reduzir sua capacidade de mobilização e reivindicação, tornando-se um tanto conformados com as situações que nem sempre aprovam. Bourdieu observou, no contexto da França, o efeito da flexibilização do trabalho:

[...] a violência estrutural também pesa sobre o que se chama contrato de trabalho [...]. No discurso empresarial nunca se falou tanto de confiança, de cooperação, de lealdade e de cultura de empresa como nessa época, em que se obtêm adesões a cada instante, fazendo desaparecer todas as garantias temporais. [...] A adesão é incerta e ambígua, porque a precariedade, o medo da demissão e do "enxugamento" pode, como o desemprego, gerar a angústia, a desmoralização ou o conformismo (BOURDIEU, 1998b, p. 140, 141).

Enquanto em vários países se questiona a flexibilização do mercado de trabalho, materializada nos chamados contratos de trabalhos, no Brasil, o desemprego e a informalidade são tão acentuados que os trabalhadores, quando conseguem estabelecer um contrato de trabalho com uma empresa, sentem-se felizes e privilegiados.

Nas entrevistas realizadas com os trabalhadores da agroindústria canavieira de Itapuranga, estes ressaltavam as vantagens de se trabalhar em regime de contrato temporário. Destacavam, entre outras vantagens, a melhoria no salário, a existência de um piso salarial, a estabilidade temporária no emprego, enfim, "direitos" a que, anteriormente, quando trabalhavam na informalidade, não tinham acesso.

Não foi possível transcrever em números o impacto que a geração de empregos trouxe ao município. Mas, pelos depoimentos orais, percebe-se que a geração de empregos provocou grande repercussão na vida da população de Itapuranga e na dinâmica de organização dos agricultores familiares. A geração de empregos reflete na vida dos agricultores familiares, principalmente porque aumenta a demanda por mão de obra, dificultando a contratação de trabalhadores temporários para auxiliar nos momentos de picos das atividades agrícolas.

No atual programa agroenergético, o Estado enfatiza que a geração e a manutenção de postos de trabalho no campo é uma característica fundamental da agricultura familiar. Sendo assim, determina que os projetos que visam à produção de energia devem considerar a geração de empregos como requisito fundamental para garantia da "sustentabilidade dos empreendimentos familiares rurais".

Caume (1997) observa que os agricultores familiares de Itapuranga utilizam prioritariamente mão de obra familiar na execução das atividades na unidade 
de exploração. No entanto, nos momentos de pico da atividade agrícola, como épocas do plantio e colheita, há maior demanda de força de trabalho, sendo necessário recorrer a outras formas de complementação de mão de obra, que se dá especialmente pela contratação de trabalhadores temporários, por meio do pagamento de diárias ou pela prática de "trocas de dias de serviço".

Segundo a Secretaria de Desenvolvimento Territorial do Vale do Rio Vermelho (MDA e SDT, 2006), a principal fonte de ocupação da força de trabalho na zona rural no estado de Goiás e em Itapuranga era a agricultura familiar. Mesmo dispondo de apenas $58,4 \%$ da área total de Itapuranga, a agricultura familiar foi responsável por 87,5\% do pessoal ocupado no município em 1996. Em função disso, Itapuranga se destacava pela sua alta capacidade de geração de empregos no meio rural, posto que 7.476 ocupações foram criadas nos estabelecimentos rurais e apenas 1.776 empregos em empresas com CNPJ.

De acordo com o MDA e SDT (2006), a geração de empregos está relacionada ao número de empreendimentos existentes no município. Em 2006, havia quatro grandes indústrias de laticínios, uma agroindústria canavieira, um frigorífico/entreposto de ovos, além de um distrito agroindustrial que demanda dos proprietários dos estabelecimentos rurais uma grande quantidade de produtos primários, possibilitando a absorção de um contingente significativo de mão de obra para trabalhar no campo. Ademais, esse município possui um grande número de agricultores familiares que geravam empregos permanentes e temporários no espaço rural.

No entanto, Itapuranga, que se destacava na geração de empregos no meio rural, atualmente enfrenta o dilema de escassez de mão de obra. O fato de a agroindústria absorver uma grande quantidade de trabalhadores exerceu uma forte pressão sobre a disponibilidade de mão de obra na zona rural. É importante notar que a agroindústria remunera melhor os trabalhadores e, mesmo oferecendo trabalho sob regime de contrato temporário, eles dispõem de mais benefícios em relação aos empregos informais que realizam junto aos agricultores familiares. A estabilidade do emprego na agroindústria também é maior do que a ofertada pelos agricultores. Na maioria das vezes, os agricultores familiares de Itapuranga só contratam mão de obra complementar nos períodos críticos do ciclo produtivo, sendo as atividades na unidade familiar realizadas normalmente pelo casal proprietário e os filhos. Outra vantagem é a remuneração quinzenal dos funcionários contratados pela agroindústria.

Como consequência, os membros da família dos agricultores precisam se esforçar para desenvolver suas atividades produtivas. Há agricultores que precisam reduzir a área cultivada com determinadas culturas, especialmente as que demandam mais mão de obra, como a fruticultura - principal vocação agrícola do município. Para sanar o problema de escassez de mão de obra, alguns agricultores intensificam a prática de trabalho comunitário, a exemplo das "trocas de dias". 
Segundo Caume (1997), a "troca de dias de serviço" era uma estratégia utilizada pelos agricultores familiares de Itapuranga para contornar o problema de escassez de mão de obra familiar. Os agricultores lançavam mão dessa prática quando havia dificuldades para contratação de mão de obra assalariada, seja pela reduzida oferta, seja por dificuldades econômicas. Além de sanar as necessidades econômicas e/ou produtivas, as "trocas de dias" também constituem momentos de socialização e convivência dos agricultores com os vizinhos e parentes. Convencionalmente, na região, a troca de dias é denominada "mutirão". Nesse sistema, quando um agricultor precisa de força de trabalho complementar, um vizinho é convidado a ajudar sob a condição de retribuir o favor e a mão de obra emprestada. Dessa forma, parentes e vizinhos se organizam para contornar as dificuldades de contratação de trabalhadores temporários com o emprego de práticas tradicionais.

Em síntese, a geração de empregos na agroindústria canavieira repercutiu no aumento da demanda por mão de obra, restringindo as possibilidades de os agricultores familiares contratarem trabalhadores temporários. Em alguns casos, precisam reduzir a área cultivada com determinadas culturas, principalmente as que são mais exigentes em mão de obra. Em consequência, precisam intensificar o ritmo de trabalho para conseguir desenvolver suas atividades agrícolas, ou recorrerem à utilização de trabalhos comunitários.

Outro desdobramento relacionado à geração de empregos pela agroindústria diz respeito à migração de trabalhadores especializados no corte de cana de outros estados da federação ou de outros municípios goianos para Itapuranga. O fato de a agroindústria canavieira do município buscar trabalhadores especializados no corte de cana de outras regiões colocou em evidência o debate público sobre a questão da violência.

As opiniões acerca do aumento da violência no município são divergentes. Alguns agentes sociais favoráveis à expansão canavieira e à atuação da agroindústria no município, como os representantes do Sindicato dos Empregadores Rurais, do Poder Público municipal, da Câmara dos Dirigentes Lojista de Itapuranga e da OAI ressaltam que antes da vinda da agroindústria para o município noticiavam-se vários furtos nas propriedades rurais, porém, com a vinda da agroindústria, a violência reduziu. Assim, a ocorrência dos crimes era justificada pelo alto índice de desemprego na cidade.

Em contrapartida, os agentes contrários à atuação do empreendimento canavieiro, especialmente os representantes da Cooperafi, do Sindicato dos Trabalhadores Rurais e da Igreja Católica, enfatizam o aumento da violência em Itapuranga. Tais temores se justificavam pelo fato de a agroindústria buscar, em outras regiões do país, pessoas "estranhas" para trabalhar na agroindústria. São recorrentes as afirmações de que os trabalhadores migrantes apresentam uma produtividade maior em relação aos cidadãos itapuranguenses, pois são especializados no corte da cana. Os agentes sociais contrários à atuação da 
agroindústria reprovam de maneira especial a contratação de trabalhadores migrantes, demonstrando receio em relação à reputação desses trabalhadores. Em seus discursos, ressaltam casos de supostos trabalhadores da agroindústria que foram pegos roubando na cidade e afirmam que alguns são fugitivos da carceragem prisional de Goiás. Além do mais, esses agentes sociais não vêem com bons olhos o fato de o empreendimento canavieiro contratar trabalhadores provenientes de outros estados ao invés de priorizar a contratação de trabalhadores do município.

Percebe-se, em alguns contextos, que as preocupações com o aumento da violência se confundem com manifestações de preconceitos. Quando indagados acerca do embasamento para a hipótese de aumento da violência, não conseguem justificar sua existência, mas não escondem o temor e a insegurança que sentem em relação às pessoas provenientes de outras regiões, especialmente os trabalhadores assalariados no corte da cana.

As preocupações são justificadas em função das características dos trabalhadores por eles denominados "nordestinos", "pessoas de aspecto estranho", "esquisitos", "feios", "cheios de tatuagem". Nas falas dos entrevistados permeiam expressões carregadas de preconceitos. Há um temor de que a cidade fique "inundada por nordestinos migrantes" de outros estados da federação e que, ao findar o ciclo da cana, podem permanecer definitivamente nas cidades, impulsionando a implantação de favelas.

Alguns representantes locais reconhecem que se trata mais de uma questão de preconceito do que propriamente de aumento da violência. A vinda dos cortadores de cana para a região provocou um choque de culturas, fato muitas vezes mal interpretado pela população itapuranguense, que passou a se sentir ameaçada. Não raramente, as suspeitas de roubos, assaltos, brigas ou confusões que ocorrem na cidade logo recaem sobre os trabalhadores migrantes. A polêmica em torno do aumento da violência é uma das repercussões decorrentes da geração de emprego pela agroindústria canavieira implantada em Itapuranga (GO). A geração de emprego já era cogitada, na esperança de conter a migração dos jovens rurais itapuranguenses, que partiam para os grandes centros ou para o exterior em busca de trabalho.

De acordo com dados da Seplan/Sepin (2009), o município de Itapuranga possui uma população total de 25.337 habitantes, sendo que, em 2007, $23 \%$ viviam no meio rural. Esse índice é relativamente alto se comparado ao percentual de $10 \%$ da população goiana que vive na zona rural. O município apresenta densidade demográfica de $19,83 \mathrm{hab} . / \mathrm{km}^{2}$, e a taxa de crescimento geométrico da população, referente aos anos de 2000 a 2008, tem sido decrescente, situando-se em torno de $-0,67 \%$.

Entre as unidades familiares pesquisadas, aproximadamente $80 \%$ dos agricultores residiam na zona rural e, em $33 \%$ dos casos, apenas o casal de agricultores permanecia no campo, sendo que seus filhos haviam migrado para 
a cidade, principalmente para Itapuranga e, em menor proporção, para outras cidades polos como Goiânia, Anápolis e Brasília, bem como outros estados, como Tocantins e Minas Gerais. Nas últimas décadas, os Estados Unidos e alguns países europeus, especialmente Portugal e Espanha, entraram na rota da migração da juventude itapuranguense.

A migração da população jovem preocupa os grupos de representação de Itapuranga. Segundo o presidente da OAI, um dos motivos que levaram a empenhar esforços para atrair a agroindústria canavieira para o município decorreu da necessidade de criar postos de trabalho para absorver os trabalhadores jovens e, por consequência, evitar sua migração. A existência de uma fábrica de processamento de cana instalada no município, porém inutilizada, também contribuiu para se dar preferência à atividade canavieira.

A migração da população jovem é uma realidade no município, dada a percepção da relação de oportunidades de vida nos espaços rurais e urbanos. Muitos agricultores reclamam do fato de os filhos não demonstrarem interesse em dar continuidade ao empreendimento familiar. Em consequência, os agricultores expressam uma previsão pessimista e uma expectativa catastrófica em relação ao futuro, como se pode perceber na entrevista realizada com uma família de agricultores:

[...] éh! Tá todo mundo indo embora. Nosso menino mesmo foi embora pra Goiânia. Daqui um tempo nossa menina vai, e só fica nóis velho no campo. E a mão de obra de tirar o leite? Porque daqui uns dias a gente não vai ter condições de fazer isso. [...] Vai ficar todas essas áreas abandonadas. Porque o nosso filho não volta mais pra trabalhar no campo, e nois não tem condições pra pagar alguém pra trabalhar!

Os jovens migram acreditando encontrar melhores oportunidades de vida e de trabalho na cidade. Eles procuram alternativas ao trabalho no campo, considerado penoso, mal remunerado e pouco gratificante. Nesse sentido, alguns empregos oferecidos pela agroindústria canavieira nem sempre são atrativos aos jovens da região.

Ademais, a expansão canavieira no município desencadeia um lento processo de migração do campo para a cidade. Ao se integrarem à agroindústria, a dinâmica social e produtiva dos agricultores familiares de Itapuranga passa por transformações consideráveis porque, ao cederem suas terras para a implantação da cultura canavieira, precisam reduzir ou abandonar o cultivo diversificado que normalmente empreendiam em suas propriedades. Em tais condições, a propriedade rural modifica sua função social, transformando-se apenas num local de habitação. Numa frequência menor, há casos de famílias de agricultores que chegam ao extremo de migrar para a cidade e passam a viver basicamente dos recursos provenientes do arrendamento da terra para a agroindústria canavieira. 
A ocorrência de migrações de agricultores familiares do campo contradiz as premissas imbuídas no Plano Nacional de Agroenergia, que difunde a promoção da tão propalada "justiça social" e suscita a promessa da interiorização do desenvolvimento por meio da redução das disparidades regionais e da "fixação das populações rural ao seu habitat" (MAPA et al., 2005a, p. 25). Dessa forma, coloca-se em questão a capacidade da atual política agroenergética de viabilizar os empreendimentos familiares rurais brasileiros.

A migração de agricultores familiares do campo, em consequência da expansão da lavoura canavieira, também foi observada por Heredia (1988) ao estudar a região dos tabuleiros alagoanos. No contexto do Proálcool, a chegada de pessoas oferecendo um preço relativamente alto pelas terras dos pequenos agricultores serviu de incentivo para a venda das pequenas propriedades. $\mathrm{Na}$ visão dos agricultores, a venda da propriedade lhes permitiria comprar outras terras situadas em áreas mais distantes e também adubos para tornar essas terras rentáveis, entretanto, muitos não conseguiram readquirir novas terras. Outros agricultores, que tinham terras situadas em áreas próximas às grandes propriedades e que resistiram à venda, foram praticamente cercados pela cana. Em algumas situações, fecharam-se as saídas de suas propriedades e, em outras, os cultivos de cana invadiram paulatinamente parte das terras dos pequenos agricultores.

Na região de Campos, segundo Neves (1981), a cultura canavieira aumentou o processo de migração. A partir da década de 1960, com a intensificação do processo de mecanização nessas atividades, agricultores reduziram suas lavouras de subsistência e passaram a se dedicar à cultura canavieira, o que resultou numa maior dependência do mercado, findando por reduzir as possibilidades de reprodução das famílias mais numerosas. As dificuldades de ampliar a terra também limitavam a reprodução dos filhos como agricultores. Assim, a unidade de produção familiar só conseguia absorver um ou dois trabalhadores produtivos, enquanto os demais deveriam partir logo que alcançasse a maturidade; por volta dos quinze ou dezesseis anos, os jovens eram incorporados ao mercado de trabalho. Através do trabalho dos filhos adultos, a unidade de produção podia reencontrar novas formas de equilíbrio, contando com eles apenas nos momentos do pico agrícola, quando isso não comprometia seus empregos na cidade.

Peres (2003) também observou que o aumento do rendimento obtido na atividade agrícola era insuficiente para garantir a reprodução social dos agricultores familiares da região de Piracicaba (SP). Com isso, os filhos abandonavam a propriedade em busca de melhores oportunidades na cidade, e os pais, em contrapartida, sofriam a carência de mão de obra para as atividades agrícolas. A alteração dos valores e das necessidades individuais influenciou no processo de migração dos filhos, pois, muitas vezes, mesmo os filhos residindo com a família, não queriam trabalhar na propriedade rural. Em outras situações, 
os pais também não queriam que os filhos trabalhassem na agricultura em função das péssimas perspectivas em relação ao futuro. Portanto, essas atitudes contribuíram para estimular a migração dos jovens.

No contexto francês, Bourdieu (2000) observa que a migração do campo decorria, além da subordinação da economia camponesa à lógica do mercado, da unificação dos "valores" rurais e urbanos que colocavam em questão a autonomia dos camponeses, levando ao enfraquecimento de sua capacidade de resistência aos atrativos da cidade. Quando perdiam sua resistência, as vantagens urbanas tornavam-se percebidas, apreciadas e atrativas a tal ponto que começavam a ser visíveis e desejáveis ao homem do campo. A atração pelo modo de vida urbano só se impõe sobre mentes convertidas à suas seduções.

De acordo com o autor, a inversão dos valores camponeses depende da posição ocupada na antiga hierarquia, mas depende também dos interesses e das disposições associadas a essa posição. Os camponeses menos resistentes às forças de atração urbanas são os menos apegados à terra, às tradições camponesas e à casa, percebendo antes e melhor do que os outros as vantagens associadas à migração, como no caso das mulheres que percebiam a migração como uma melhor opção em face do que o futuro no campo lhes reservava - o casamento e a sujeição ao marido. Os agentes menos apegados à condição camponesa são também os menos empenhados no trabalho e nas responsabilidades de poder, são menos apegados à propriedade rural e mais dispostos a estudar, pois acreditam nas promessas de mobilidade social que a educação difunde.

Esses agentes trazem ao mundo camponês o "olhar citadino" que despreza, desvaloriza e desqualifica as características camponesas: sua cultura, seus produtos, seu modo de produção, sua linguagem, seu estilo, sua roupa, suas maneiras, seu físico, enfim, tudo o que as famílias camponesas têm a oferecer perde seu encanto. A unificação dos espaços rurais e urbanos neutraliza os mecanismos sociais que garantiam aos camponeses franceses - nos limites restritos do espaço social onde viviam - a liderança simbólica de um espaço particular, que lhes permitia a perpetuação dos valores fundamentais do grupo e, por conseguinte, sua existência como camponeses. Com isso, o mundo fechado onde as pessoas se sentiam interligadas e em casa, foi aos poucos se abrindo (BOURDIEU, 2000).

$\mathrm{O}$ autor ainda observa que a desmoralização camponesa resulta do rompimento das barreiras que separavam as relações sociais de base local, que ajudavam a camuflar a realidade desfavorável da posição ocupada pelos camponeses no espaço social. O camponês começou a observar a sua condição por comparação com as pessoas da cidade, que já não é abstrata e imaginária como antigamente. Tal comparação se dá no interior da própria família, em relação aos parentes que migraram. Ou seja, o camponês passou a perceber-se como "camponês", no sentido pejorativo, segundo uma lógica de "racismo". 
Bourdieu (2000) explica que isso não acontece de uma hora para outra, pois os agentes precisam de tempo para comparar e compreender as vantagens e desvantagens do campo e da cidade. Esse tempo é diferente para cada pessoa e depende do apego ao mundo antigo e dos interesses que cada pessoa deposita nesse mundo. Os diferentes agentes percorrem velocidades distintas, conforme os interesses que investem no campo e na cidade. A característica mais visível da atual crise que os camponeses vivenciam se exprime nas "profecias" pessimistas do tipo "nós somos fracos"; essa derrota interiorizada individualmente leva a resultados não desejados, como a migração.

Segundo Bourdieu (2000), a imagem catastrófica do futuro coletivo, como a "profecia" que anuncia o desaparecimento dos camponeses, só reforça a probabilidade de isso realmente acontecer, uma vez que confere sentido aos múltiplos indícios parcelares que a experiência cotidiana oferece. O efeito desmoralizador exercido pela representação pessimista do futuro, expressa pelo próprio grupo, pode contribuir para o seu declínio. A desmoralização atua como uma previsão, ou seja, uma profecia capaz de remeter ao advento do futuro que profetiza. Assim, os agentes interiorizam uma ideia de futuro e realizam ações que tendem a ameaçar a sua própria reprodução, como as migrações maciças, resultantes do somatório de fugas individuais. No entanto, os camponeses, ao invés de profetizarem um futuro catastrófico, devem se apossar de meios que permitam ao grupo obter o controle da crise e organizar-se com vistas a opor-se aos problemas que vivenciam.

Em suma, a migração da população jovem de Itapuranga pode estar relacionada a questões não diretamente relacionadas ao desemprego no campo. Nesses termos, a geração de postos de trabalho pela agroindústria canavieira pouco repercute na reversão do processo migratório observado no município; ao contrário, tende a intensificá-lo.

\subsection{Alterações na dinâmica produtiva dos agricultores integrados}

Outra influência decorrente da vinda da agroindústria canavieira para Itapuranga (GO) refere-se à substituição de culturas alimentares pela cultura da cana. Essa questão também remonta entre os aspectos negativos relacionados ao Proálcool, que trouxe como consequência a redução da oferta de alimentos. Contudo, é importante indagar até que ponto o programa determinou a substituição de culturas alimentares, uma vez que vários autores levantam essa questão.

Um estudo de repercussão sobre a substituição de culturas, de autoria de Mello e Fonseca (1981), revelou que o Brasil enfrentaria um conflito na realização de seus objetivos que eram a produção de alimentos - como arroz, feijão, milho, mandioca, batata, cebola, batata-doce e tomate -, de produtos voltados para exportação - como laranja, soja, café etc. -, além da produção de biomassa para 
obtenção de energia, proveniente de culturas como cana-de-açúcar, mandioca, entre outros. Observando-se o crescimento de áreas destinadas à cultura da cana-de-açúcar, entre 1977 e 1980, os autores constataram que a meta de produção de culturas energéticas para obtenção de álcool foi completamente atingida em 1980 e a meta de produção de culturas para exportações foi contemplada em $60 \%$ a $70 \%$, enquanto que o objetivo de produção de culturas alimentares não foi cumprido.

No estado de São Paulo, onde se concentrou a produção canavieira, a situação foi pior: entre 1976 e 1980, a área colhida com cana-de-açúcar teve incremento de $46,6 \%$. Já nas culturas alimentares básicas observaram-se resultados negativos, a exemplo do arroz, milho e mandioca, que tiveram redução de área de 50,5\%, $23,3 \%$ e $23,3 \%$, respectivamente. Em Alagoas, para um incremento de 55,2\% das áreas colhidas de cana, houve decréscimo de $30 \%$ no cultivo do arroz, de 5,6\% no do feijão e de $27,1 \%$ no da mandioca. Em Pernambuco, a cana teve acréscimo de $10,9 \%$, enquanto o arroz teve queda de $20 \%$, a mandioca de $1,5 \%$ e o milho de 11\% (MELLO e FONSECA, 1981). Constata-se uma realocação de recursos na agricultura, visando estimular o aumento da área plantada com cana-de-açúcar em detrimento das culturas alimentares e das pastagens.

Com base em dados do IBGE, Magalhães et al. (1991) demonstraram que a área colhida com culturas alimentares, entre 1960 e 1985, aumentou 94\%, ficando praticamente igual ao incremento da população, que foi de $93 \%$. Embora a produção de alimentos tenha sido superior ao crescimento da população, a oferta alimentar não foi satisfatória quando se leva em conta a elevação dos padrões de consumo. Durante os 25 anos de análise, o produto por habitante no país expandiu cerca de $3 \%$ a.a., mas para atender a elevação do produto por habitante, a oferta de alimentos deveria subir 1,11\% a.a. Sendo assim, o incremento da produção total de alimentos deveria ter sido de $153,7 \%$, e não de $138 \%$, como observado. Porém, os resultados para as culturas energéticas foram bem mais substanciais, apresentando incremento de $123 \%$ na área plantada.

Portanto, o aumento de produção das culturas alimentares, entre 1960 e 1985, foi inferior ao das culturas energéticas e de exportação, que aumentaram $254 \%$ e $292 \%$, respectivamente. Já em relação ao estado de São Paulo, a produção de alimentos no período analisado teve elevação de apenas 55\% , ficando abaixo do incremento populacional, que foi de 129\%. Em contrapartida, o esforço do Estado para aumentar as lavouras energéticas e de exportação superou os resultados obtidos no restante do país, apresentando aumento na produção de $483 \%$ e $314 \%$ para as culturas energéticas e de exportação, respectivamente (MAGALHÃES et al., 1991).

Magalhães et al. (1991) reconhecem a existência de uma redução da oferta de alimentos durante o Proálcool, entretanto, os autores defendem que a redução da oferta de alimentos não se deve à expansão da cultura canavieira. Para isso acontecer, seria necessário que todas as terras produtivas do país 
estivessem ocupadas de tal forma que o aumento na área plantada com um produto implicasse na redução da área disponível para outros e, no Brasil, isso não acontece, pois são imensas as áreas de terras inaproveitadas. No entanto, consideram que são indisponíveis para plantio os solos que não dispõem de um mínimo de infraestrutura como: estradas, instalações para armazenamento, energia elétrica, serviços de apoio agrícolas, políticas agrícolas, entre outros. Então, atribuem a responsabilidade pela debilidade na oferta de alimentos à ausência dessa infraestrutura e de políticas de estímulo. Apesar de não ser a intenção dos autores, suas justificativas apenas confirmam que o Estado, por meio das políticas públicas instituídas para o setor agrícola, viabilizou as condições de infraestrutura e de crédito rural para produção de culturas de exportação e de agroenergia em detrimento da produção de culturas alimentares.

No Plano Nacional de Agroenergia, o Estado se preocupa, no plano do discurso, em evitar a substituição de culturas alimentares pela cultura canavieira, devido às críticas e repercussões ocorridas no âmbito do Proálcool que levaram, em parte, ao enfraquecimento do programa junto à sociedade. Sendo assim, entre as vantagens associadas ao novo programa agroenergético, ressaltam a possibilidade de se aumentar os cultivos energéticos sem que isso afete a produção de alimentos. Caso contrário, como prevê o próprio Estado, o programa perderá sua legitimidade social: “[...] a expansão da área de agricultura energética não poderá ocorrer à custa da contração da oferta de alimentos, [...] sob pena de forte reação contrária da sociedade, o que inviabilizaria o negócio da bioenergia" (MAPA et al., 2005b, p. 30).

Também, o governo de Goiás minimiza os impactos das políticas agroenergéticas na produção de gêneros alimentícios, destacando que a expansão da cultura da cana-de-açúcar se dará basicamente nas áreas de pastagens. No entanto, os estudos de Castro et al. (2008) revelam que a atual distribuição das agroindústrias, induzida pelo setor produtivo, concentra-se nos principais eixos rodoviários que servem o Centro-Sul Goiano, visto que os empreendimentos canavieiros seguem preferencialmente as direções das estradas BR-153, BR-060, BR-364 e BR-452. Sendo assim, a tendência é que a cana substitua, especialmente, áreas já consolidadas com culturas anuais, como a soja e o milho e áreas de pastagens, aproveitando a infraestrutura já existente. Dessa forma, as culturas anuais e a pecuária serão empurradas para as regiões Norte e Noroeste do estado, provocando consideráveis transformações produtivas nos diferentes espaços regionais.

Em Goiás, já se evidenciam conflitos entre distintas cadeias produtivas que atualmente competem com o complexo canavieiro. Nos últimos anos, Goiás se destacou na produção de grãos, principalmente soja e milho que, somado às políticas de incentivo fiscal, atraiu especialmente para o sudoeste goiano as cadeias produtivas de aves e suínos, consolidando os complexos produtivos de grãos, leite e de carnes de suínos e aves. Várias prefeituras estudam a 
implementação de dispositivos legais com vistas a limitar as áreas de expansão da cultura da cana-de-açúcar, a exemplo do que ocorreu em Rio Verde, que concentra o complexo da soja, alavancado pela instalação da empresa Perdigão no município. Em 2006, a prefeitura de Rio Verde promulgou uma lei limitando o cultivo da cana-de-açúcar no máximo de 10\% das áreas agricultáveis, no intuito de evitar a queda na oferta de grãos que compõem a matéria-prima das rações dos animais. Outras prefeituras, como a de Mineiros, Quirinópolis e Santa Helena de Goiás cogitam fazer o mesmo. Estes conflitos de interesses entre as diferentes cadeias produtivas do agronegócio põem em evidência que, em Goiás, a cultura canavieira não está substituindo somente áreas de pastagens degradadas.

Outra questão preocupante refere-se à expansão canavieira em áreas de agricultura familiar. No estudo realizado em Itapuranga (GO), foi possível constatar essa situação. Observa-se que a cana vem adentrando em áreas de agricultura familiar e redefinindo um novo contexto socioeconômico no município.

O sistema de produção desenvolvido pelos agricultores familiares de Itapuranga está orientado para a diversificação produtiva, visando atender às necessidades alimentares da família e à comercialização. Os agricultores familiares que possuem uma área de terra reduzida, de até 15 hectares, além de se dedicarem à produção de gêneros alimentícios e à criação de pequenos animais (galinhas, suínos e alguns bovinos), cultivam hortaliças e frutíferas destinadas basicamente à comercialização. Já os agricultores que possuem uma área maior têm como atividade principal a pecuária leiteira, além de produzirem culturas alimentares e frutíferas.

Segundo dados do Seplan/Sepin (2009), em 2008, os principais produtos cultivados pelos agricultores de Itapuranga foram milho, arroz, feijão e as frutíferas (maracujá, melancia, banana, mamão, abacaxi). Em 2006, do total de 16.712 hectares destinados à produção agrícola do município, a cultura do milho ocupou $32,9 \%$, a do arroz, $15,8 \%$ e a produção de frutas ocupou $10,2 \%$ da área. Já em 2008, a área total destinada à produção agrícola municipal reduziu para 13.645 hectares, e as culturas de milho, arroz e frutíferas somaram, juntas, apenas $27,9 \%$ da área. Vale notar que as áreas destinadas à pastagem não entram no cálculo.

A análise dos dados da Seplan/Sepin (2009), referente ao município de Itapuranga, aponta redução na área cultivada com milho que, em 2000, ocupava uma área expressiva de 6.000 hectares, sendo que, em 2008, foram plantados apenas 2.400 hectares, portanto, redução de $60 \%$. A área destinada ao cultivo de arroz e feijão também teve queda, pois, em 2000, os dois cultivos somavam área de 2.200 hectares cultivados. Em 2008, o arroz e o feijão passaram, respectivamente, para 800 e 100 hectares. Também houve baixa na área destinada ao cultivo de frutas, principalmente de maracujá e melancia. Em 2000, 1.250 
hectares eram utilizados para o cultivo do maracujá e, em 2008, eram apenas 280 hectares, redução da ordem de $77,6 \%$ da área plantada. O cultivo da melancia se dava numa área de 400 hectares em 2000, e foi reduzido para menos da metade em 2008.

Os agricultores familiares de Itapuranga demonstram preocupação em relação à substituição de culturas alimentares pela cana, que poderá repercutir na falta de alimento e no encarecimento dos preços dos alimentos. Os agricultores perceberam um aumento nos valores dos produtos que comercializam nas feiras do município, o que consideram positivo, pois melhora a remuneração oriunda de seu trabalho. No entanto, temem que esse aumento se estenda aos demais produtos agrícolas que adquirem no mercado.

Também o secretário da Agricultura de Itapuranga prevê redução na oferta de alimento no município e ressalta que isso levará ao aumento dos preços algo satisfatório aos produtores. Acredita que a elevação das cotações para o agricultor vai estimular a produção de alimentos, limitando o crescimento da cultura canavieira.

De fato, a cana-de-açúcar foi a única cultura que teve incremento significativo em termos de área cultivada no município. Em 2000, a área cultivada com cana era de apenas 20 hectares; em 2008, ocupava 9.500 hectares, revelando, portanto, expressivo incremento de área, da ordem de $47.000 \%$. A cultura canavieira já ocupa 8,5\% da área total do município. A agroindústria canavieira implantada na região informou que pretende atingir 12.000 hectares de área plantada, perfazendo $10 \%$ da área total do município até 2012.

Apropriando-se da teoria de Adam Smith sobre a mão invisível do mercado, o secretário defende que o mercado tende a buscar seu próprio equilíbrio. Ele espera que as próprias condições do mercado consigam restringir o crescimento da cultura da cana-de-açúcar, o que de certa forma isenta o poder municipal de tomar atitudes no intuito de estimular a produção de gêneros alimentícios. No entanto, a história confirma a ineficácia deste propalado equilíbrio para a agricultura, que apresenta como característica a imprevisibilidade e a dependência de fatores não totalmente controláveis pelo homem, como por exemplo, o clima, as condições naturais, entre outros. Ademais, a segurança alimentar é uma atribuição do Estado que não pode ser relegada à "mão invisível do mercado".

No que se refere à restrição da expansão canavieira por meio de leis municipais que limitam a área a ser ocupada pela cana - a exemplo do ocorrido em Rio Verde, ou à instituição de programas de fortalecimento da agricultura familiar municipal -, o secretário da Agricultura reafirmou que isso não será necessário, pois o próprio mercado tende a restabelecer seu equilíbrio.

É provável que a expansão canavieira no município tenha desencadeado um processo de substituição das culturas alimentares. Durante a pesquisa, evidenciou-se que a cultura da cana-de-açúcar se estabeleceu em áreas que antes 
eram destinadas às culturas anuais, como arroz, milho, feijão e outras, sendo o milho a principal cultura substituída. Porém, a cana substituiu, prioritariamente, áreas destinadas à pecuária. De maneira geral, os quintais rurais, situados nas adjacências das residências - usados para os cultivos de pomar e horta, para as criações de galinhas e suínos, bem como para as edificações das instalações dos bovinos de leite -, sempre são preservadas. A maioria dos agricultores familiares preservou também uma parte da propriedade onde cultivam alguns gêneros alimentícios, geralmente, áreas de baixadas que correspondem a áreas de mata ciliar, pois as consideram mais férteis e úmidas. Assim, agricultores integrados à agroindústria passaram a concentrar suas atividades produtivas na área restante, mantendo a diversificação produtiva.

Ao ceder suas terras à agroindústria, agricultores familiares tiveram que se desfazer de alguns animais bovinos. Aqueles que possuem áreas reduzidas, para não se desfazerem por completo do rebanho, optaram por arrendar áreas de outros agricultores para continuar criando um pouco de animais. Essa prática é viável porque o preço do arrendamento das pastagens custa aproximadamente metade do preço pago pela agroindústria. Porém, o aumento da demanda de terras para arrendamento no município logo implicará na elevação dos preços do arrendamento das áreas de pastagens.

Na região de Campos (RJ), Neves (1981) também constatou que alguns agricultores, apesar de cultivarem cana para fornecer à usina, não abandonavam os cultivos de subsistência e a criação de gado, a qual era vista como uma atividade complementar, que atendia às necessidades de reserva de valor $\mathrm{e}$ ajudava a cobrir os custos de produção da lavoura canavieira. No entanto, o fato de possuírem uma área de terra reduzida - até cinco alqueires de terra obrigava os agricultores a utilizarem pastos alugados ou de beira de estrada para o exercício da atividade.

Entre os agricultores familiares entrevistados, a cultura canavieira ocupou, prioritariamente, aquelas áreas formadas com pastagens. A justificativa dos agricultores para a redução das áreas anteriormente destinadas a pastagens, na maioria das vezes, remontava ao baixo valor pago aos agricultores pelo litro do leite, tido como insuficiente para cobrir os custos de produção.

Conforme explicitado no Plano Safra Territorial (MDA et al., 2007), desde 2003 foram realizados vários investimentos do Pronaf infraestrutura (Proinf) e de outros contratos com o MDA no território, visando expandir eixos de desenvolvimentos prioritários. Um deles é o da pecuária leiteira, para o qual foram adquiridos aproximadamente 28 tanques de resfriamento de leite para atender agricultores de todos os municípios do Território do Vale do Rio Vermelho de Goiás (exceto Itapirapuã), totalizando $\mathrm{R} \$ 542.500,00$ de investimentos nessa atividade, além de cursos de capacitação. Todavia, observa-se que, apesar dos investimentos no período compreendido entre 2000 e 2005, a produção de leite do território apresenta uma pequena queda de menos de 1\%; mas, nos 
municípios de Carmo do Rio Verde, Itapuranga e Guaraíta ocorreram baixas em torno de $30 \%$.

Dados disponibilizados pela Seplan/Sepin (2009) demonstram que, em 2006, havia no município de Itapuranga 87.500 aves (cab), 9.400 suínos (cab), 130.000 cabeças de bovinos e 23.300 vacas ordenhadas (cab) que rendiam uma produção leiteira de 23,1 milhões de litros. Na Figura 1, é possível observar a evolução do efetivo da pecuária entre 2002 e 2006. Percebe-se, a partir de 2002, uma tendência decrescente do efetivo da pecuária de Itapuranga em todas as categorias analisadas. É pouco provável que a cultura da cana-de-açúcar seja a única responsável pela redução do efetivo da pecuária do município, o que remete a problemas presentes no interior da própria cadeia produtiva, como o aumento dos custos de produção, a redução dos preços que desestimulam o exercício da atividade, principalmente, da pecuária leiteira. Nesse contexto, a expansão canavieira no município surge como uma opção a mais para produtores rurais que tendem a substituir as atividades menos rentáveis pela produção de cana de forma integrada com a agroindústria.

Figura 1. Evolução do efetivo da pecuária do município de Itapuranga, 2002-2006.

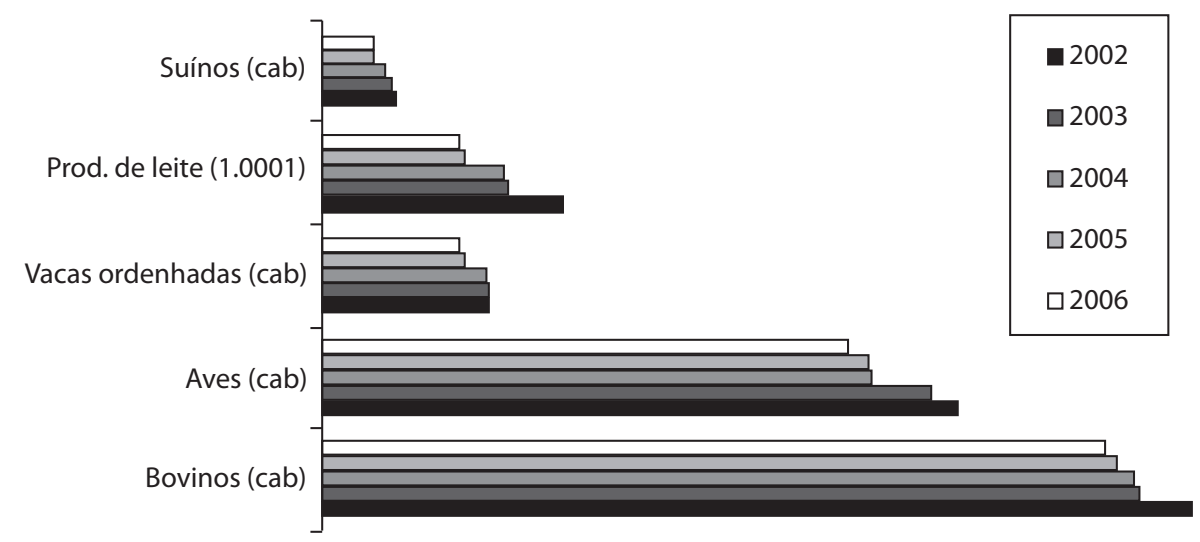

Fonte: IBGE, citado em Seplan/Serem, 2009.

Em suma, observou-se redução da área destinada a culturas alimentícias e frutíferas, bem como a redução do efetivo de bovinos na região. Vale notar que a cana-de-açúcar foi a única cultura que teve incremento significativo em termos de área cultivada no município e, provavelmente, seja a responsável pela redução nas demais atividades agropecuárias em Itapuranga. No correr da pesquisa, observou-se que a integração dos agricultores à agroindústria, apesar de recente, foi suficiente para provocar alterações consideráveis em sua dinâmica produtiva, visto que, de uma forma ou de outra, agricultores tentavam 
se adequar à nova conjuntura que presenciavam. Muitos agricultores tiveram que readequar e remanejar seus esforços, intensificando suas atividades em áreas reduzidas. Alguns passaram a se dedicar mais intensamente a atividades como a fruticultura e a horticultura, em que a rentabilidade por área é maior e necessitam de menor extensão de terra, como também à criação de pequenos animais, principalmente galinhas e suínos. Outros agricultores, após cederem suas áreas de pastagens para o plantio de cana, passam a arrendar terras de outros agricultores para manterem a criação de gado.

\section{Considerações finais}

A nova conjuntura socioeconômica delineada pela atividade canavieira em Itapuranga gera processos contraditórios que repercutem na dinâmica organizacional dos agricultores familiares. Os reflexos destes processos são particularmente visíveis nos desdobramentos da geração de empregos, nas questões referentes à migração e nas polêmicas em torno da violência.

A geração de empregos pelo empreendimento canavieiro constitui um processo contraditório que, se por um lado, atende aos anseios da população, por outro, reduz a oferta de mão de obra necessária para suprir as unidades de exploração familiar. Como consequência, os agricultores precisam alterar sua forma de organização, conduzindo os membros da família a um maior esforço ou mesmo a recorrer à prática de trabalho comunitário. Em outros casos, altera a dinâmica produtiva levando os agricultores a reduzir os cultivos mais exigentes em mão de obra.

Os empregos ofertados pela agroindústria pouco repercutiram na reversão do processo migratório observado entre os jovens. Ao contrário, desencadeou um lento processo de migração de agricultores familiares do campo para a cidade, uma vez que, ao cederem suas terras para a implantação da cana, os agricultores precisaram reduzir ou abandonar seus cultivos diversificados. Em outras situações, a propriedade rural modificou sua função social, transformando-se apenas num local de habitação. Embora em menor frequência, há casos de famílias que chegam ao extremo de migrar para a cidade, abandonando a vida no campo.

O fato de a agroindústria canavieira buscar trabalhadores em outros estados da federação colocou em evidência o debate em torno da violência. Em determinados contextos, seus desdobramentos se confundem com manifestações de preconceitos aos trabalhadores migrantes, fomentando, no conjunto da sociedade, sentimentos de preconceito.

O desenvolvimento da atividade canavieira em Itapuranga (GO) interferiu na oferta e nos preços dos gêneros alimentícios. Ao mesmo tempo em que 
os agricultores familiares temem a falta de alimentos, com o consequente encarecimento dos preços dos produtos que precisam adquirir no mercado, percebem uma melhora no rendimento familiar decorrente do aumento dos preços dos produtos que comercializam.

A análise da ocupação do espaço produtivo do município aponta para a redução nas áreas de culturas alimentares, de frutíferas e também no efetivo da pecuária. A cana é a única cultura que apresenta incremento de área cultivada. Possivelmente, a redução das áreas de culturas alimentares, de frutíferas e do efetivo da pecuária decorre de problemas presentes no interior das próprias cadeias produtivas, que desestimulam o exercício de determinadas atividades, o que remete à prioridade, dada pelo Estado, para as culturas agroenergéticas em detrimento das demais atividades agropecuárias.

\section{Referências Bibliográficas}

BRANDÃO, C. R. Campesinato goiano: três estudos. Goiânia: UFG, 1986.

BOURDIEU, P. Coisas ditas. São Paulo: Brasiliense, 1990.

. A miséria do mundo. Petrópolis: Vozes, 1997.

EDUSP, 1998 a.

. Contrafogos: táticas para enfrentar a invasão neo-liberal. Rio de Janeiro: Jorge Zahar, 1998 b.

. O campo econômico: a dimensão simbólica da dominação. Campinas: Papirus, 2000.

BRASIL. Lei Federal no 11.326 de 24 de julho de 2006 "Conceitua Agricultor Familiar e Empreendedor Familiar Rural". Diário Oficial da União, Brasília, DF, 27 jul. 2007. Disponível em: http://www.mda.gov.br. Acesso em: 11 out. 2007.

CARVALHO, S. P. Agricultura familiar e agroindústria canavieira: integrações e contradições. 2008. Dissertação (Mestrado em Agronegócio) - Universidade Federal de Goiás, Goiânia, 2008.

CASTRO, S. de S.; BORGES, R. de O.; AMARAL, R. Estudo da expansão da cana-deaçúcar no estado de Goiás: subsídios para uma avaliação do potencial de impactos ambientais. Disponível em: http://arruda.rits.org.br Acesso em: 15 ago. 2008.

CAUME, D. J. A agricultura familiar no estado de Goiás. Goiânia: Editora UFG, 1997. 
Censo Agropecuário (1996). Disponível em: http://www.ibge.gov.br Acesso em: 10 jun. 2009.

HEREDIA, B. M. A. de. Formas de dominação e espaço social: a modernização da agroindústria canavieira de Alagoas. São Paulo: Marco Zero, 1988.

MAGALHÃES, J. P. de A.; KUPERMAN, N.; MACHADO, R. C. Proalcool: uma avaliação global. Rio de Janeiro: ASTEL, 1991.

MAPA; MCT; MME; MDI\&CE (2005a). Diretrizes de politica de agroenergia 2006 -2011. Disponível em: http://www.mapa.gov.br. Acesso em: 22 abr. 2007.

; SPA; EMBRAPA (2005b). Plano nacional de agroenergia 2006-2011. Brasília: EMBRAPA, 2005. Disponível em: http://www.embrapa.br. Acesso em: 22 abr. 2007. ; . Plano Nacional de Agroenergia Revisado 2006-2011. 2ª ed. rev. Brasília: EMBRAPA, 2006. Disponível em: http://www.embrapa.br. Acesso em: 22 abr. 2007.

MDA ; SDT. Plano Territorial de Desenvolvimento Rural Sustentável. Estudo propositivo para dinamização econômica do território rural do Oeste Rio Vermelho. Brasília, 2006. ; SAF. Plano Safra Territorial Vale do Rio Vermelho Goiás. Brasília, 2007.

MELLO, F. H. de ; FONSECA, E. G. da. Proálcool, energia e transportes. São Paulo: Pioneira (FIPE), 1981.

NEVES, D. P. Lavradores e pequenos produtores de cana: estudo das formas de subordinação dos pequenos agricultores ao capital. Rio de Janeiro: Zahar editores, 1981.

- Agricultura familiar: quantos ancoradouros! Disponível em: http:// www.prudente.unesp.br. Acesso em: 08 out. 2007.

PERES, A. M. de P. O arrendamento de terras na pequena propriedade fundiária canavieira: o caso do município de Piracicaba. 2003. Dissertação (Mestrado) Instituto de Economia, UNICAMP, Campinas, 2003.

SEPLAN/SEPIN Goiás em dados 2007. Disponível em: http://www.seplan.go.gov. br/sepin/ Acesso em: 15 nov. 2008.

. Perfil socioeconômico de Itapuranga. Disponível em: http://portalsepin. seplan.go.gov.br/. Acesso em: 8 ago. 2009.

UDOP Política de investimento gera empregos em Goiás. Disponível em: http://www. ufop.com.br Acesso em: 11 jul. 2009. 
